\title{
Uncommon applications of statistical methods of the design of experiments in chemical technology and environment protection
}

\author{
Grzegorz Lewandowski, Jan Ćwirko \\ Szczecin University of Technology, Institute of Organic Chemical Technology, ul. Pułaskiego 10, 70-322 Szczecin, Poland, \\ e-mail: grzegorz.lewandowski@ps.pl
}

\begin{abstract}
The review of literature related to the applications of statistic methods of design of experiments in chemical technology and environment protection was presented in the work. The research that consists of two stages: a stage of choosing the best variables describing an experimental object and a stage of proper experimental investigation, seems particularly interesting.

An interesting example of an application of statistical strategies in environmental protection is the optimization of photoactivity of $\mathrm{TiO}_{2} / \mathrm{SiO}_{2}$ mixture, received by a sol-gel technique. $\mathrm{TiO}_{2}$, due to its specific feature, was applied in the photocatalytic methods of removing toxic compounds from water and air. In the experiments there were used two designs - the fractional factorial design $2^{5-1}$ (as the elimination one) and the central composite design (as the proper one). Following the data analysis from the elimination plan two variables were eliminated, which helped to simplify the research object.

Among other uncommon applications of the design of experiments: the optimization of the conditions for the extraction of natural pigments used in dyeing food, the production of fatty acid methyl esters used as diesel oil substitutes (biodiesel) and the optimization of a supercritical fluid extraction methodology for the analysis of castor oil, should be mentioned.
\end{abstract}

Keywords: design of experiments, optimization, central composite designs, dyes, esterification, $\mathrm{TiO}_{2}$ photoactivity, biodiesel.

Presented at VII Conference Wasteless Technologies and Waste Management in Chemical Industry and Agriculture, Międzyzdroje, 12 - 15 June, 2007.

\section{INTRODUCTION}

The dependences occurring among different input variables, which take parts in the chemical process and output variables are an important issue in chemical technology. Each new process needs to define these dependences, in terms of quality and quantity, generally by experimental methods. In order to do this, there are used statistic methods of the design of experiments. They enable decreasing a number of experiments to minimum taking all the important parameters into consideration. In chemical technology, a design of experiments, is used mainly to improve the quality of selection, to design a new technology, for preliminary experimental research ${ }^{\mathbf{1 - 3}}$ and optimization ${ }^{\mathbf{4}, 5}$.

In this work the literature related to applying statistic methods of the design of experiments in chemical technology and environment protection, was reviewed.

\section{PHOTOACTIVITY OF TIO $_{2}{ }^{6}$}

An interesting example of an application of statistical experimental methods is the optimization of $\mathrm{TiO}_{2}$ photoactivity in a mixture with $\mathrm{SiO}_{2}$. A great interest in $\mathrm{TiO}_{2}$, results from its specific feature, such as acceptable band gap energy, non-toxicity and resistance to photocorrosion. The aim of the experiments was to receive a mixture of $\left(\mathrm{TiO}_{2}+\mathrm{SiO}_{2}\right)$ having an optimal photoactivity. At the first stage 5 variables were selected and tested: $\mathrm{A}-$ weight percentage of $\mathrm{TiO}_{2}$ in $\left(\mathrm{TiO}_{2}+\mathrm{SiO}_{2}\right), \mathrm{B}-$ concentration of $\mathrm{HNO}_{3}$ (catalyst), $\mathrm{C}-$ molar ratio of $\mathrm{H}_{2} \mathrm{O} / \mathrm{Si}, \mathrm{D}$ - calcination temperature and $\mathrm{E}$ - calcination temperature rise rate. The answer function was a conversion degree of methyl orange. The experiments were performed according to the fractional factorial design $2^{5-1}$ and the main effects and the interaction effects were determined.
Table 1. Factors and levels for the modified central compos-

\begin{tabular}{|c|c|c|c|}
\hline \multicolumn{3}{|c|}{ Factors } \\
\hline & \multicolumn{3}{|c|}{ Level } \\
\hline-2 & A & B & C \\
\hline-1 & 20 & 0.015 & 2 \\
\hline 0 & 30 & 0.045 & 3 \\
\hline 1 & 40 & 0.075 & 4 \\
\hline 2 & 50 & 0.105 & 5 \\
\hline & 60 & 0.135 & 6 \\
\hline
\end{tabular}

Table 2. The experimental data for the empirical model building by the central composite design

\begin{tabular}{|l|r|r|r|r|}
\hline \multirow{2}{*}{ Run } & \multicolumn{3}{|c|}{ Factor } & \multirow{2}{*}{ Conversion, \% } \\
\cline { 2 - 4 } & A & B & C & 45.9 \\
\hline 1 & -1 & -1 & -1 & 71.5 \\
\hline 2 & 1 & -1 & -1 & 43.8 \\
\hline 3 & -1 & 1 & -1 & 61.2 \\
\hline 4 & 1 & 1 & -1 & 52.1 \\
\hline 5 & -1 & -1 & 1 & 77.9 \\
\hline 6 & 1 & -1 & 1 & 57.7 \\
\hline 7 & -1 & 1 & 1 & 83.1 \\
\hline 8 & 1 & 1 & 1 & 86.8 \\
\hline 9 & 2 & 0 & 0 & 48.5 \\
\hline 10 & -2 & 0 & 0 & 63.7 \\
\hline 11 & 0 & 2 & 0 & 59.3 \\
\hline 12 & 0 & -2 & 0 & 75.6 \\
\hline 13 & 0 & 0 & 2 & 37.6 \\
\hline 14 & 0 & 0 & -2 & 61.0 \\
\hline $15(\mathrm{C})$ & 0 & 0 & 0 & 65.5 \\
\hline $16(\mathrm{C})$ & 0 & 0 & 0 & \\
\hline
\end{tabular}

For the next the stage only these variables, which had the highest effect were selected: A, B and C. The experiments were performed using central composite design (Table 1 and 2). An adequate regressive polynomial was received.

The highest (100\%) degree of photocatalytic conversion of methyl orange was received at the highest values of $\mathrm{A}$ and $\mathrm{C}$ factors (Figure 1). Both decrease in the molar ratio 


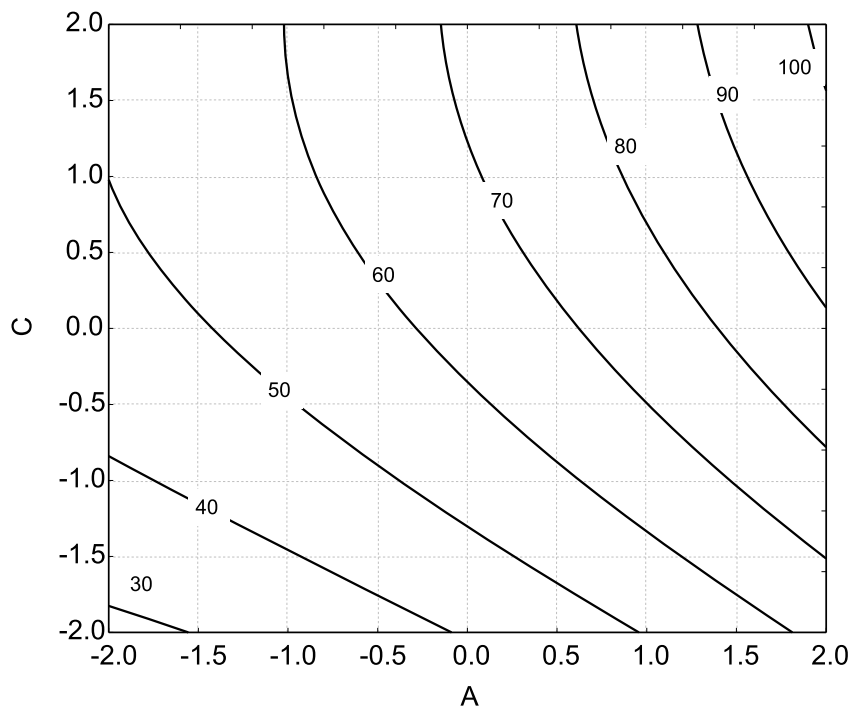

Figure 1. The contour lines of methyl orange conversions with factors $\mathrm{A}\left(\mathrm{TiO}_{2}\right.$ weight percentage) and $\mathrm{C}\left(\mathrm{H}_{2} \mathrm{O} / \mathrm{Si}\right.$ molar ratio)

of $\mathrm{H}_{2} \mathrm{O} / \mathrm{Si}(\mathrm{C})$ as well as the concentration of $\mathrm{TiO}_{2}$ (A) decreases the degree of methyl orange conversion, which proves a decrease in the photoactivity of the obtained material.

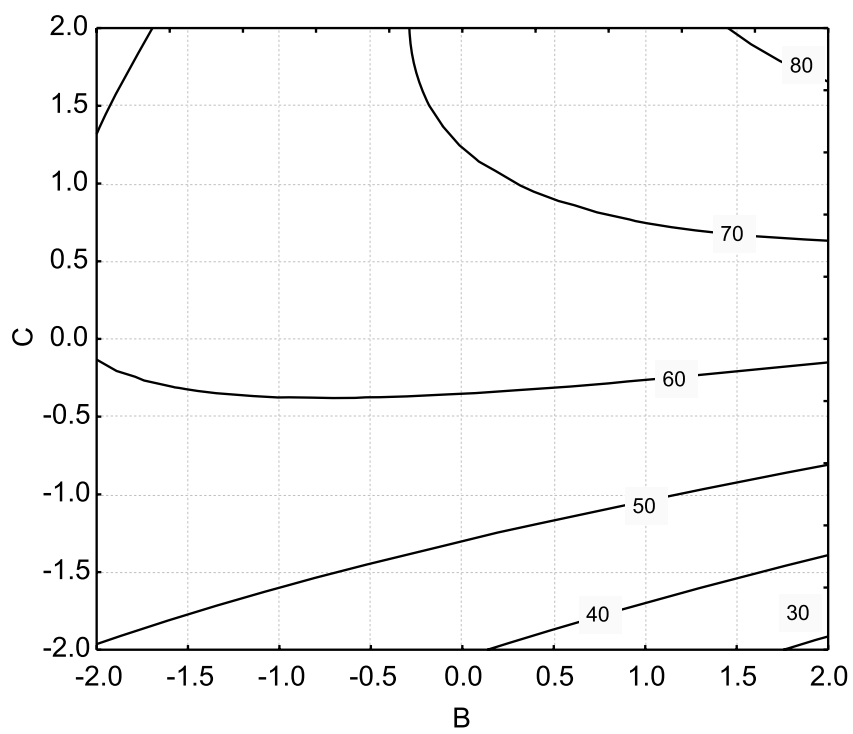

Figure 2. The contour lines of methyl orange conversions with factors $\mathrm{B}\left(\mathrm{HNO}_{3}\right.$ concentration) and $\mathrm{C}\left(\mathrm{H}_{2} \mathrm{O} / \mathrm{Si}\right.$ molar ratio $)$

The large curvature of the contour lines reflects the existence of a significant interaction effect between the $\mathrm{B}$ and $\mathrm{C}$ factors (Figure 2). An analysis of Figure 2 reveals that the runs with the high levels of $\mathrm{B}$ and $\mathrm{C}$ factors receive the maximum degree of methyl orange conversion at the range of $90 \%$. The lowest value of the answer function in the tested range of the parameters changes was received at the lowest value of $\mathrm{C}$ and the higher value of $\mathrm{B}$. However, it should be noticed that the influence of the $\mathrm{C}$ factor is much bigger (Figure. 2). The photoactivity decreases in the order of $\mathrm{B}(+)$ and $\mathrm{C}(+), \mathrm{B}(-)$ and $\mathrm{C}(+), \mathrm{B}(-)$ and $\mathrm{C}(-)$, and $\mathrm{B}(+)$ and $\mathrm{C}(-)$, if Figure 3 is divided into four parts. The other interactions are not important.

Additional experiments of the influence of nitric acid concentration on the methyl orange conversion with the molar ratio $\mathrm{H}_{2} \mathrm{O} / \mathrm{Si}$, as the parameter (Figure 4), prove the existence of a strong interaction between them.

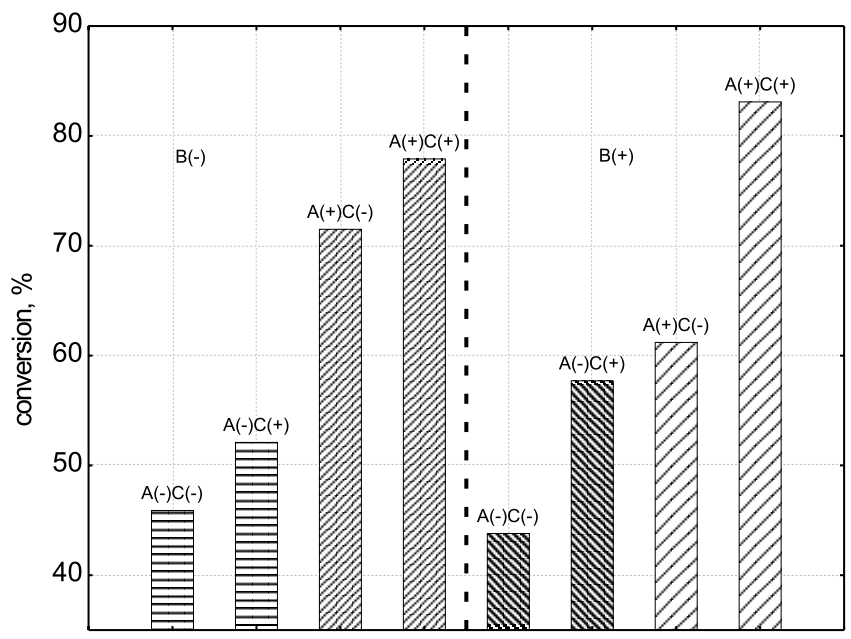

Figure 3. The effects of factors $\mathrm{A}\left(\mathrm{TiO}_{2}\right.$ weight percentage), B $\left(\mathrm{HNO}_{3}\right.$ concentration), and $\mathrm{C}\left(\mathrm{H}_{2} \mathrm{O} / \mathrm{Si}\right.$ molar ratio) on the photocatalytic conversions of methyl orange

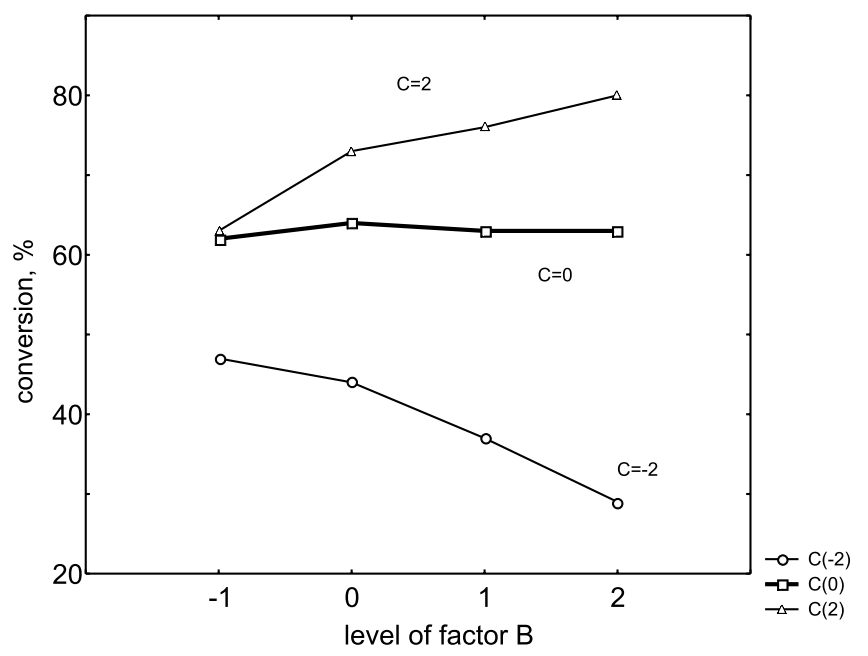

Figure 4. Real experimental results of the methyl orange conversion with factors $\mathrm{B}\left(\mathrm{HNO}_{3}\right.$ concentration) and $\mathrm{C}\left(\mathrm{H}_{2} \mathrm{O} / \mathrm{Si}\right.$ molar ratio $)$

In the tested ranges of input variables an optimum photoactivity the mixture of $\mathrm{TiO}_{2} / \mathrm{SiO}_{2}$ was received at the concentration of $\mathrm{TiO}_{2}-60 \%$, the molar ratio of $\mathrm{H}_{2} \mathrm{O} / \mathrm{Si}$ -6 and the concentration of $\mathrm{HNO}_{3}-0.135 \mathrm{M}$. Under such conditions, the absorption band of the received material $\mathrm{TiO}_{2} / \mathrm{SiO}_{2}$ was $>400 \mathrm{~nm}(410 \mathrm{~nm})$, which indicates that the maximum usage of solar energy takes place (lack of blue shift of the absorption band that decreases the utilization of solar energy).

\section{PIGMENTS IN COCHINEALS ${ }^{7}$}

Another interesting example of using the statistic methods of planning the experiments can be the optimization of the pigment extraction from insects. One of the sources of receiving a natural red pigment is cochineal (Dactylopius coccus Costa) an insect, from which, a known pigment carmine acid, is received. Apart from carminic acid, cochineal has also got other pigments but in smaller amounts. A critical step of the process is the extraction of the pigments from the insect body. Samples of cochineal (female) were dried at the temperature of $60^{\circ} \mathrm{C}$ till the water was completely removed and then they were ground. Samples of the same mass $(0.125 \mathrm{~g})$ were later mixed with the methanol/ 
water solution (65:35, v:v) and homogenized. The pigments were extracted for 30 minutes at the temperature of $80^{\circ} \mathrm{C}$, and then cooled and centrifuged. This procedure was repeated $\mathrm{n}$ times. The method of extraction described above was optimized using small composite designs (Draper-Lin experimental plans). At the first stage of the experiments an estimation of the influence of four variables (temperature of extraction, time of extraction, methanol concentration in the extraction mixture and the number of extractions) on the extraction capacity was performed. Statistic analysis of the results showed, that in the most cases the effects were caused by changing a number of extractions. The rest of the tested factors were found to be not significant. In further experiments the second experimental plan, which consisted of 10 observations ( 4 factorial design $2^{2}$ points, 4 star points and 2 points in the centre of the design) was used (Table 3).

Table 3. The design matrix and response values of the pigment from cochineal

\begin{tabular}{|l|c|c|c|}
\hline Run. & Temp. $\left[{ }^{\circ} \mathrm{C}\right]$ & Methanol $[\%]$ & Carminic acid $\tilde{Y}$ a \\
\hline 1 & 80 & 70 & 77 \\
\hline 2 & 80 & 60 & 100 \\
\hline 3 & 50 & 70 & 74 \\
\hline 4 & 65 & 60 & 74 \\
\hline 5 & 80 & 50 & 76 \\
\hline 6 & 65 & 50 & 75 \\
\hline 7 & 65 & 60 & 76 \\
\hline 8 & 50 & 60 & 71 \\
\hline 9 & 50 & 50 & 71 \\
\hline 10 & 65 & 70 & 74 \\
\hline
\end{tabular}

${ }^{\text {a N}}$ Normalized response (relationship between area for each run and the area for the run with maximal response)

Time of extraction (30 $\mathrm{min})$ and a number of extractions $(n=2)$

were on the constant level

Factors, which have the most important influence on the extraction efficiency, were the temperature of the process and the number of extractions (Figure 5). The temperature could not be over $80^{\circ} \mathrm{C}$, because under such conditions carmine acid is decomposed.

\section{SUPERCRITICAL FLUID EXTRACTION ${ }^{8}$}

The aim of the experiment was an optimization of a supercritical fluid extraction/ enzymatic reaction process

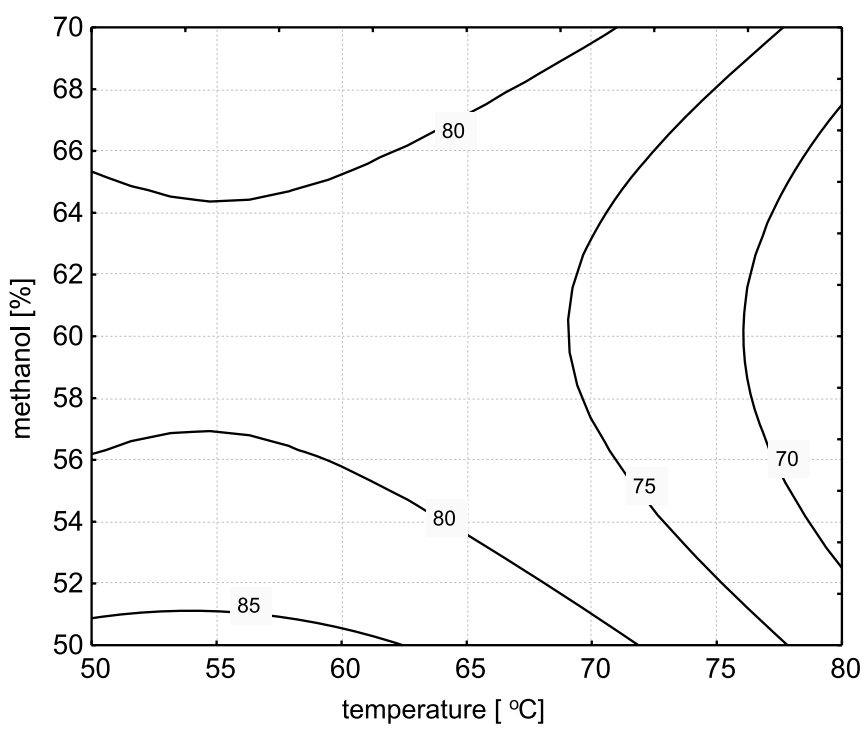

Figure 5. The response surface estimated for the carminic acid

for the determination of the fatty acids composition of castor seeds.

Oil from castor seeds (Ricinus communis L.), is highly viscous as it contains a high amount $(\sim 90 \%)$ of the hydroxy fatty acid ricinoleic acid. The oil has got many industrial applications, for example, in the production of synthetic polymers, lubricants, paints, coatings, and cosmetics. Conversion oil to fatty acid methyl esters (FAMEs) in castor seeds was performed by using lipase from Candida antarctica (Novozyme 435, $1 \mathrm{~g}$ in each sample), which catalyses the methanolysis reaction in supercritical carbon dioxide. The experiments were performed basing on BoxBehnken $\left(3^{(k-p)}\right)$ design. As input values methanol concentration $\left(\mathrm{x}_{1}\right)$, water concentration $\left(\mathrm{x}_{2}\right)$, temperature $\left(\mathrm{x}_{3}\right)$, and pressure $\left(\mathrm{x}_{4}\right)$ were chosen. The response function was the yield of FAME from castor oil. The estimated input variables of the reduced regression model, obtained from the experimental data, were presented in Table 4.

A high yield of FAME was received performing extraction under the pressure of $300 \mathrm{bar}$, at the low water concentration $(0.2 \%)$, the high methanol concentration $(5 \%)$ and at the temperature $80^{\circ} \mathrm{C}$. The results showed that better yield can be received at higher methanol concentration and

Table 4. The parameter estimates for Novozyme 435

\begin{tabular}{|c|c|c|c|c|c|}
\hline Variable & $\mathrm{df}$ & Estimate $\left(b_{i}\right)$ & SE & $t$-value & $\operatorname{Pr}>|t|$ \\
\hline$b_{0}$ & 1 & -887.7 & 515.814 & -1.72 & 0.1015 \\
\hline $\mathrm{x}_{1}$ & 1 & 191.43 & 85.1369 & 2.25 & 0.0366 \\
\hline$x_{2}$ & 1 & -4912.8 & 2128.42 & -2.31 & 0.0324 \\
\hline $\mathrm{X}_{4}$ & 1 & 8.5742 & 2.82802 & 3.03 & 0.0069 \\
\hline$x_{4}{ }^{2}$ & 1 & -0.01256 & 0.00432 & -2.91 & 0.0090 \\
\hline $\mathrm{X}_{4} \mathrm{X}_{1}$ & 1 & -0.52746 & 0.27868 & -1.89 & 0.0737 \\
\hline $\mathrm{X}_{4} \mathrm{X}_{2}$ & 1 & 14.491 & 6.96690 & 2.08 & 0.0513 \\
\hline
\end{tabular}

$\mathrm{DF}$ - degrees of freedom, MS - mean of square, $\mathrm{t}$ - value for the Student's $t$ distribution, $\mathrm{Pr}-$ probability

Table 5. The determination of FAMEs in castor seeds using the optimized method compared with the conventional methodology

\begin{tabular}{|c|c|c|c|c|c|}
\hline \multirow[b]{2}{*}{$\begin{array}{l}\text { Castor seed } \\
\text { no. }\end{array}$} & \multicolumn{2}{|c|}{ Conventional method } & \multicolumn{3}{|c|}{ SFE/enzyme method } \\
\hline & $\begin{array}{c}\text { FAME } \\
\text { (mg/g seed) }\end{array}$ & RSD (\%) & FAME (mg/g seed) & $\begin{array}{c}\text { RSD } \\
(\%)\end{array}$ & $\begin{array}{c}\text { Recovery } \\
(\%)\end{array}$ \\
\hline 1 & 545.6 & 6.7 & 556.8 & 4.6 & 102.1 \\
\hline 2 & 591.1 & 2.8 & 568.6 & 2.5 & 96.2 \\
\hline 3 & 542.8 & 1.2 & 486.1 & 4.9 & 89.6 \\
\hline av & & 3.6 & & 4.0 & 95.9 \\
\hline
\end{tabular}

${ }^{a}$ temperature $\left(80^{\circ} \mathrm{C}\right)$, pressure $(300 \mathrm{bar})$, and methano I concentration ( $7 \mathrm{vol} \%$ ), water concentration $(0.020$ vol\%), time 90 min. Oil contents of the seeds were approximately $56,55,55 \%$ for castor seeds 1,2 , and 3 , respectively. RSD - relative standard deviations 
Table 6. The composition of FAMEs in castor seeds using the optimized method compared with the conventional methodology

\begin{tabular}{|l|c|c|c|c|r|r|}
\hline \multirow{2}{*}{ FAME } & \multicolumn{3}{|c|}{ Conventional method } & \multicolumn{3}{c|}{ SFE/enzyme method } \\
\cline { 2 - 7 } & \multicolumn{3}{|c|}{ castor } & sastor \\
\cline { 2 - 7 } & seed 1 & seed 2 & seed 3 & seed 1 & seed 2 & seed 3 \\
\hline C16:0 & 0.90 & 0.87 & 1.68 & 0.41 & 0.42 & 1.44 \\
\hline C18:0 & 0.83 & 1.00 & 1.53 & 0.78 & 0.90 & 1.35 \\
\hline C18:1(9) & 3.10 & 3.55 & 3.68 & 2.60 & 3.19 & 2.99 \\
\hline C18:1(11) & 0.21 & 0.36 & 1.09 & 0.35 & 0.34 & 0.51 \\
\hline C18:1(9,12) & 4.66 & 3.42 & 4.38 & 4.10 & 4.20 & 3.56 \\
\hline C18:1(9,12,15) & 0.44 & 0.39 & 0.59 & 0.41 & 0.39 & 0.41 \\
\hline C20:1(11) & 0.14 & 0.27 & 0.93 & 0.43 & 0.58 & 0.88 \\
\hline C18:1(9)OH(12) & 89.73 & 90.13 & 86.11 & 90.91 & 89.97 & 88.96 \\
\hline
\end{tabular}

${ }^{a}$ temperature $\left(80^{\circ} \mathrm{C}\right)$, pressure $(300 \mathrm{bar})$, and methanol concentration $(7 \mathrm{vol} \%)$, water concentration $(0.020$ vol\%), time $90 \mathrm{~min}$

at lower water concentration. This was the reason for performing complimentary experiments with methanol and with water extending the range of the previously tested concentrations. Extraction of oil was performed the most effectively at the concentration of 7 and $0.02 \%$ of methanol and water, respectively. Under such optimum conditions a determination of the total content and composition of FAMEs (Table 5 and 6) in three different castor seeds was performed, and it was compared to a conventional method (organic solvent extraction followed by acid-catalyzed transmethylation). The analysis of the data from Table 5 shows that both methods bring similar effects with an average recovery value amounting to $96 \%$.

\section{ESTERIFICATION OF SUNFLOWER OIL ${ }^{9}$}

Fatty acids methyl esters (FAMEs) can be also used as diesel substitutes, and they are known as biodiesel. Biodiesel can be used directly or mixed with conventional fuel for diesel engines, and as a heating fuel. Biodiesel is synthesized from direct transesterification of vegetable oils, where the corresponding triglycerides react with a short-chain alcohol, usually methanol in the presence of a catalyst. Vegetable-based fuels are biodegradable, non-toxic and significantly reduce the level of air pollutions.

The process of biodiesel production was optimized by using the factor plan and the method of the answer surface. Basing on the preliminary experiments of the esterification process of the refined sunflower oil with methanol it was established that a catalyst, which brought the highest conversion was sodium hydroxide. There were taken two factors for the optimization: temperature $\mathrm{X}_{\mathrm{T}}$ and catalyst concentration $\mathrm{X}_{\mathrm{C}}$. The molar ratio of methanol/triglyceride was constant and was $6 / 1$. The conversion of triglycerides
Table 7. The experimental matrix for the central composite design

\begin{tabular}{|l|c|c|c|c|r|}
\hline Run & $\mathrm{T}\left({ }^{\circ} \mathrm{C}\right)$ & $\mathrm{C}(\mathrm{wt} \%)$ & $\mathrm{X}_{\mathrm{T}}$ & $\mathrm{X}_{\mathrm{C}}$ & $\mathrm{Y}_{0}(\%)$ \\
\hline 1 & 25 & 0.5 & -1 & -1 & 86.0 \\
\hline 2 & 65 & 0.5 & 1 & -1 & 98.1 \\
\hline 3 & 25 & 1.5 & -1 & 1 & 99.7 \\
\hline 4 & 65 & 1.5 & 1 & 1 & 100.0 \\
\hline 5 & 45 & 1 & 0 & 0 & 97.7 \\
\hline 6 & 45 & 1 & 0 & 0 & 97.8 \\
\hline 7 & 45 & 1 & 0 & 0 & 97.6 \\
\hline 8 & 45 & 1 & 0 & 0 & 98.0 \\
\hline 9 & 45 & 1.71 & 0 & 1.414 & 100.0 \\
\hline 10 & 73.3 & 1 & 1.414 & 0 & 99.7 \\
\hline 11 & 16.7 & 1 & -1.414 & 0 & 96.6 \\
\hline 12 & 45 & 0.29 & 0 & -1.414 & 89.0 \\
\hline
\end{tabular}

to methyl esters $\mathrm{Y}_{\mathrm{o}}$ (answer of the system) was measured after four minutes of reaction. The first performed experiments were related to the factorial design for two variables (Table 7, experiments from 1 to 8 ).

The first four rows correspond to the $2^{2}$ design. Four additional runs (next four rows of the matrix) were carried out at the centrepoint, coded 0 , to estimate the overall curvature effect. A statistical analysis was carried out on the experimental results, and the two main effects and interaction effect were estimated (Table 8). The initially taken linear model was not adequate. Because of this four additional runs, called star points and coded $\pm \alpha$ were added to the $2^{2}$ factorial plus centrepoints to form a central composite design (Table 7 , rows $1-12$ ).

There were established optimum conditions of methyl ester production: mild temperature $\left(20-50^{\circ} \mathrm{C}\right)$ and high catalyst concentration (1.3\%). Both these factors had a positive influence on the system answer, and the effect caused by catalyst concentration was larger than that of temperature. The effect of interaction temperature-catalyst

Table 8. A statistical analysis for the $2^{2}$ factorial design

\begin{tabular}{|c|c|}
\hline Response: & Conversion to $\mathrm{ME}$ after $4 \mathrm{~min}$. \\
\hline Number of experiments: & 4 \\
\hline Degrees of freedom: & 3 \\
\hline Main effects and interaction effect: & $\mathrm{I}_{\mathrm{T}}=6.2, \mathrm{I}_{\mathrm{C}}=7.8, \mathrm{I}_{\mathrm{TC}}=-5.9$ \\
\hline Significance test: & Student's $t$ \\
\hline Confidence level: & $95 \%$ \\
\hline Average of factorial runs, $Y_{\mathrm{m}}$ : & 95.95 \\
\hline Standard deviation, S: & 0.1707 \\
\hline Student's $t$-value: & 3.181 \\
\hline Confidence interval: & \pm 0.2715 \\
\hline Significance effects: & $\mathrm{I}_{\mathrm{T}}, \mathrm{I}_{\mathrm{C}}, \mathrm{I}_{\mathrm{TC}}$ \\
\hline \multicolumn{2}{|l|}{ Significance curvature: } \\
\hline Average of centrepoint responses, $\mathrm{Y}_{\mathrm{c}}$ : & 97.775 \\
\hline Curvature: & $Y_{m}-Y_{c}=1.825$ \\
\hline Confidence interval of curvature: & \pm 0.3824 \\
\hline Significance: & Yes \\
\hline Response equation: & $Y=a_{0}+a_{1} X_{T}+a_{2} X_{C}+a_{12} X_{T C}$ \\
\hline
\end{tabular}


concentration was negative, probably because of side reactions, such as soap formation; it was especially seen at higher temperature $\left(>60^{\circ} \mathrm{C}\right)$ and catalyst concentration $(>1.5 \%)$.

\section{LITERATURE CITED}

(1) Hendershot R. J., Rogers W. B., Snively Ch. M., Ogunnaike B. A., Lauterbach J.: Catal. Today, 2004, 98, 375 -385 .

(2) He Y, Bao Y. D.: Renewable Energy, 2005, 30, 805 813.

(3) van Ginkel S., Sung S., Lay J. -J.: Environ. Sci. Technol., 2001, 35, 4726 - 4730 .

(4) Cole D. C., Pagano N., Kelly M. F.,Ellingboe J.: J. Comb. Chem., 2004, 6, $78-82$.

(5) Gooding O. W.,Vo L., Bhattacharyya S., Labadie J.: J. Comb. Chem., 2002, 4, 576 - 583.

(6) Lung-Chuan Chen, Chao-Ming Huang: Application of statistical strategies to process optimization of sol-gel derived $\mathrm{SiO}_{2}$ modification of $\mathrm{TiO}_{2}$, Ind. Eng. Chem. Res., 2004, 43, 6446 - 6452 .

(7) Gonzales M., Mendes J., Carnero A., Lobo M. G., Afonso A.: Optimizing conditions for the extraction of pigments in cochineals (Dactylopius coccus Costa) using response surface methodology, J. Agric. Food Chem., 2002, $50,6968-6974$.

(8) Turner Ch., Whitehand L. C., Nguyen T., McKeon T.: Optimization of a supercritical fluid extraction/reaction methodology for the analysis of castor oil using experimental design, J. Agric. Food Chem., 2004, 52, 26 - 32.

(9) Vicente G., Coteron A., Martinez M., Aracil J.: Application of the factorial design of experiments and response surface methodology to optimize biodiesel production, Ind. Crops and Products, 1988, 8, 29 - 35 . 